\title{
Israeli Physicians' Performance after Sleep Deprived Situations - Differences among Male and Female Hospital Residents
}

\author{
Dafna Kariv ${ }^{1}$, Itamar Offer ${ }^{2}$, Netta Notzer ${ }^{3}$ and Eran Dolev $^{4}$ \\ 1. College of Management, School of Business Administration, Rishon LeZion, Israel; \\ 2. Department of Pediatrics B, Schneider Children's Medical Center of Israel, Petah Tiqva, Israel; \\ 3. Department of Medical Education and 4. Department of Behavioral Sciences, Sackler \\ Faculty of Medicine, Tel Aviv University, Israel
}

KEYWORDS Sleep-derived situations; professional performance; fatigue; safety

\begin{abstract}
This paper explores gender differences among hospital residents' performance of clinical tasks in sleepderived situations. Two different research instruments were employed to investigate the physicians' performance: an objective measure assessing the effects of sleep loss on performance by means of a computer game, and a subjective measure, a self-evaluation questionnaire investigating physicians' assessments of the effects of sleep loss on their professional performance. The results reveal no significant differences in objective performance between men and women as obtained by the computer game after a night shift. However, significant gender differences in selfassessment appeared in the self-reported questionnaire in the domains of technical abilities, decision-making and general functioning. Women residents reported a significant decline in some components of their performance after a night shift, while male residents report only a marginal effect on their performance. The major contribution of this study is in its actual applications in developing optimal work schedules and organizational interventions to minimize fatigue and increase safety.
\end{abstract}

\section{INTRODUCTION}

In the present research we were concerned with the gender differences of male and female hospital physicians in their actual performance of assigned cognitive and mechanical tasks as compared with their self-assessments of the quality of their performance of several professional on-the-job tasks. Much of previous research has focused on widely shared perceptions of differential gender-based competence in the execution of certain professional tasks: men have been considered more capable in "general performance" and in tasks demanding greater mechanical competence, rationality and assertion while women were considered better at tasks necessitating nurturing and provision of services, and in roles entailing expressions of caring and sympathy (Fiske et al., 2002; Wagner and Berger 1997). Although perceptions of many aspects of gender differences in performance have changed to some degree, empirical studies have found that both men and women continue to appraise men

Address for Correspondence: Dafna Kariv, $\mathrm{PhD}$, The School of Business Administration, The College of Management, P.O. Box 9017, Rishon LeZion 75190 Israel Phone: 972-3-9634281

E-mail: dafiran@nonstop.net.il;

karivd@colman.ac.il as generally more capable and that men are more valued socially and appraised as more competent than women (Fiske et al., 2002; Williams and Best, 1990), especially insofar as the important aspects of competitive, high-ranking professions are concerned (Wagner and Berger, 1997; Ridgeway and Correll, 2000). Moreover, there is a large corpus of studies indicating that individuals, especially women, are far from precise selfevaluators when judging their own abilities: men overestimate and women underestimate performance on tasks gender-typed as masculine while men and women are both more accurate on those gender-typed as feminine (Beyer, 1995; Beyer and Bowden, 1997; Furnham, 2005).

One possible explanation for such differences asserts that perceptions of gender-based differences in performance often represent what we think "most people" believe or accept as true about men's and women's dissimilar proclivities. As such, individuals modify their behavior and bias their evaluations accordingly (Foschi 1996; Lovaglia et al., 1998; Steele 1997). The consequences might be: (a) performance modification - a modification of work-related behaviors and performance by both men and women in relation to the shared perceptions of men's and women's dissimilar tendencies; and (b) gender-based perceptions of gender differen-tiated competence, 
since shared perceptions may produce a pro-male bias in evaluating men's performance of certain types of tasks that accord men higher performance ratings than women in specific professions, and that can therefore evoke gender-differentiated standards for attributing performance to an ability (Maurer and Taylor, 1994; Robbins and DeNisi, 1993). According to a different interpretation of such shared percep-tions, each gender's selfassessments of competence in task fulfillment are based on pre-conceived notions of gender-based capabilities. The self-assessments that men and women make of their own competence at their work-related tasks might thus also be biased due to the shared perceptions flourishing in their specific environments. Differentiation in men and women's performance suitability, and specifically a pro-male bias, has been found when the occupation is traditionally viewed as a man's job and the situation is viewed as competitive.

These perspectives underlie the central interest of the present study, which is an attempt to discern modifications in performance that appear to have developed in competitive environments, in this case in the work world of hospital physicians, and gender-based perceptions regarding men's and women's professional performance. Specifically, are there any objective and/or subjective differences in performance of occupational tasks by each gender, that is, of men as a group and of women as a group?

For the purpose of this study and by addressing the limitations of previous research in measuring performance we adapted two different research tools: a computer game that simulated participants' performance and a self-reported questionnaire representing the participants' selfassessment on their performance. The participants were hospital residents, and the tools were administered twice, once before the commencement of a day shift and again after the completion of a night shift, thus indicating performance in normal as well as in sleep-deprived situations.

Our focus on sleep-deprived situations allowed for the partial control of intervening effects in our attempt to explore both the respondents' actual performance of professional tasks and their self-assessments of their performance, since it served as a reference point vis-à-vis their attempt to rank the quality of their performance of several tasks, that is, "before night-duty" and "after completion of a shift of night duty." This is specifically relevant in the work world of physicians since professional performance fluctuates across shifts, and validity pitfalls and deficiencies might emerge through residents' potential replies on their overall performance. Other reference points could have been used as well, but since hospital residents frequently experience night-shifts, the sleep-deprived situation played a dual role, serving as a reference point and constituting a routine and familiar situation.

\section{Performance of Male and Female Professionals}

The accumulated research on gender differences in performance levels presents a mixture of results, with some empirical studies not indicating any significant differences between the genders in performance (Hall et al., 1990; Guzman and Frank, 2004), while in others some discrepancies between the genders emerge, with men appearing to perform better in terms of completion of tasks, output and even in effective decision-making and assertiveness towards achievement of goals (Grantcharov et al., 2001; Watson, 2002) - all of which are related to the concept of "masculine" competences. A third group of studies shows women performing better, though only in specific positions and situations; this is apparently due to the measurements of certain interpersonal skills that more frequently depict female performance strengths (Jackson and Joshi, 2001; Lewis, 1997) associated with "feminine" abilities. In both cases, a larger number of stereotypically masculine characteristics in a given profession negatively affects women's achievements, while in environments encompassing traits that are more stereotypically feminine ones, women are better in both performance and achievement (see e.g., Gorman, 2005; Kelinske et al., 2001).

However, a more in-depth examination of these studies on gender and performance illuminates questions regarding several subjects relevant to our inquiry: definition of performance at work; measurement of performance; and control of indirect effects on gender (e.g., demographic characteristics). Since each of these subjects can be defined and measured in very different ways, the generalizations regarding the empirical results described above may be compromised.

Performance at work is a multifaceted endeavor (Sider et al., 2001; Sturman et al., 2005); it can be conceptualized as an individual's overall 
performance and task proficiency, as performance in specific dimensions such as the quality or the quantity of work done, and more. Its empirical exploration is based to a large extent on unidimensional tools that are addressed to the measures of outcome of the performance, while neglecting, or ignoring, the measures of process (Eddy, 1998; Griffith et al., 2002; Legnini et al., 2000; Treasure et al., 2002). Since the composite construct of performance is even more complex in clinical situations, the definition and measurement of performance at work should encompass a sufficient number of different aspects of the occupational demands.

Thus, considering men or women as advantaged, or as being better in their work performance than their opposite-gendered counterparts appears to be irrelevant, but the prevalence of such widespread perceptions means that a more complicated measurement has to be employed in order to obtain accurate measurements of men's and women's performance levels in specific situations. Uni-dimensional measurements, such as those usually employed, may illustrate only certain specific aspects of performance and neglect others; thus, at least two methodological tools should be employed in order to broaden the spectrum of measurement of performance. Moreover, instead of measuring performance itself, some studies employ performance appraisal procedures in order to determine gender differences in performance (Brienza et al., 2004; Crossley and Davis, 2005), which in turn may have been based on gender biases in evaluating performance (Hind and Baruch, 1997; Pazy and Oron, 2001; Viswesvaran et al., 2005). The employment of two measures thus might reduce such biases.

Finally, gender differences in performance are perceived in the context in which the task takes place; hence, gender-related variables should be taken into account when observing these differences, such as status, seniority, age, genderrelated professional behaviors or even cognitive gender-related styles or time spent at tasks (Bonanno and Kommers, 2005; Eagly and Wood, 1999), all of which induce variables determining the differences obtained in the performance levels of men and women professionals. In clinical work environments, gender-related professional behaviors appear crucial in leading to differences in performance: studies show that female physicians tend to identify different health problems than those recognized by their male colleagues (specifically in instances of "social" and "metabolic" problems), spend more time with patients compared to their male colleagues, and have a greater tendency to provide continuity care (Bensing et al., 1993; Britt et al., 1996). Thus, controlling such gender-related variables is required in the investigation of gender and performance at work.

In conclusion, the research on gender and professional performance reveals several methodological pitfalls. This suggests a need for the exploration of gender differences in professional performance through a more inclusive methodological process.

\section{Performance in Sleep-deprived Situations}

Sleep-deprived situations are a stressful yet usual state that hospital residents experience. Although there is a secure body of evidence indicating that performance declines due to the fatigue resulting from sleep deprivation (AncoliIsrael and Weinger, 2002; Dorrian et al., 2000; Dula et al., 2001; Fletcher et al., 2003), the majority of the studies do not show any significant effect of gender on performance in such situations. However, although women were found to selfperceive a consequent deterioration in their performance when sleep-deprived more often than men (Defoe et al., 2001), their actual performance when sleep-deprived has not been found to differ significantly from that of their male counterparts (Fulco et al., 2001).

A recent study by Papp et al. (2004) presents results indicating a major impact of sleep loss on physicians' abilities to perform their professional work, but no gender differences appeared. Other studies, from the field of aviation research, addressed differences between the ability of sleep-deprived male and female pilots to withstand combat stressors and their ability to maintain cognitive performance; they found that gender produced no operationally significant effects on any of the performance domains examined (Caldwell and LeDuc, 1998; Chelette et al., 1998). Another study (Grantcharov et al., 2003) examined the results, measured by a trainer-virtual reality, of repetitions of six identical clinical tasks that surgeons were asked to perform during a daytime shift and after a night on call. The authors found no significant gender differences in the measures of performance of these tasks in terms of error, 
but differences emerged in terms of how long it took to perform the tasks. Further studies investigating these findings revealed certain genderrelated differences in bio-psychological processes among women that indicated that fatigue develops more slowly in women than in men (Fulco et al., 2001; Mourtazaev et al., 1995), an attribute that could reveal higher performance levels among women while sleep-deprived, as compared to men. Insofar as self-evaluation is concerned, the findings showed that when fatigue occurs, it leads to women exhibiting relatively higher levels of psychological and mental distress (Matuszek et al., 1995), which could lead to relatively lower self-evaluations of their performance when affected by fatigue.

The cited literature addresses differences in the genders' self-assessments of their performance, with mixed findings emerging in the context of their objective performance. Since the measurement of "performance" lacks uniformity, these findings should be reconsidered through valid methodological tools and procedures.

\section{Hypotheses}

Based on the cited literature on the differences in men's and women's self-assessments of performance in both "normal" and sleep-deprived situations, we postulated that:

1. Men's and women's self-assessments of the effects of sleep deprivation on their professional performances differ: women assess their performance as negatively affected by sleep deprivation more than men do.

Though the results in the literature on gender and professional performance are mixed, no significant gender differences emerged in performance when sleep-deprived. From this perspective we hypothesized further that:

2. Men's and women's objective performance when sleep-deprived will exhibit no significant differences.

In our aim to isolate indirect gender-related effects on either self-assessed performance or on objective simulated performance, we introduced personal and job-related determinants on the basis of the following hypothesis:

3. The perceived effects of sleep loss on men and women physicians' self-assessments on their professional performance and on their objective performance will remain substantial after accounting for personal and job-related determinants.

\section{METHOD}

\section{Study Population}

A group of one hundred and fifty-three pediatric residents, 71 female and 82 male, working in three Israeli medical centers ${ }^{1}$ participated in the study. The residents typically work rosters that include two to four eight-hour day shifts and two to three 16-hour night shifts per week.

We asked each participant to provide information regarding the following personal and job-related determinants: (1) number of night shifts per month; (2) average hours of sleep per night shift; (3) actual hours of sleep during the night shift just ended; (4) self-evaluation of the complexity of the night shift just ended; (5) number of hours into a night shift after which performance begins to decline; (6) number of years of seniority in the specialization program; and (7) gender.

In order to control, at least partially, genderrelated differences in their clinical work world (Bensing et al., 1993; Britt et al., 1996), which might have an indirect impact on the results of this study, and to maintain a more homogeneous and uniform group and thus reduce indirect effects, we included only pediatric residents in the present study.

\section{The Study Tools}

Defining and measuring job performance is a complex task. The use of multiple tools to measure performance in research has been rare to date, although most researchers agree that performance measurement should rely on more than one process measure (Schul and Wren, 1992); specifically, measures that can be justified with an objective, evidence-based rationale should be used along with subjective measures, such as self-reports or self-assessments.

The present study avoids problems relating to the use of a single performance assessment, or the use of performance appraisals as a research tool obtaining an "objective" view, by using two different measures. The first, the objective measure, is a problem-solving computer game, and the other, subjective measure, is a selfassessment questionnaire; both probe factors of relevance to physicians' professional performance.

While self-assessment questionnaires are well 
established in the literature as tools for subjectively assessing performance both in normal and in sleep-deprived situations, no widely accepted objective evaluation tools are available for this purpose. The use of computer games in this context, although new and relatively innovative, has been found to be valid and reliable (e.g., Rosekind et al., 1995; Smith-Coggins et al., 1994; Taffinderet al., 1998).

The Objective Tool: We employed a Tetris computer game (TCG) to assess the respondents' actual performance in completing the game in both normal and sleep deprived situations. One advantage of using computer games is that the cognitive activity of the players during game-play replicates human behavior, especially in the revelation of differences in players' performance (Kavakli and Gero, 2002; Kavakli and Thorne, 1999; Rappaport, 1997), for example in terms of technical ability, concentration, how problems are encountered, help-seeking behavior, and shortand long-term decision-making (Suwa et al., 1998). Researchers in cognition point out that some games require players to develop complex strategies that involve high-level cognitive abilities, such as drawing inferences from implicit information and estimating risk (Pillay, 2002).

We chose a Tetris computer game that is simple to operate and learned relatively easily and rapidly (Demaine et al., 2004). More importantly, the TCG selected has been precisely quantified and found to be a valid means of measuring alertness and concentration (Haier et al., 1992), which are major components of clinical professional performance. The TCG requires players to make assumptions about risks, draw on their memories, and make decisions. Since clinical professional performance involves alertness, concentration, effective decision-making and problem solving (ABIM Foundation, 2002; ABIM Foundation; ACP-ASIM, 2003²), we consider the TCG to be a suitable means of obtaining accurate measures of objective performance parameters under sleep-deprived and non-sleep-deprived, or normal, conditions.

The Subjective Tool: A self-reported questionnaire (SRQ) was used to obtain respondents' evaluations of their professional performance in sleep-deprived situations, i.e., after working a night shift. The questionnaires were distributed to all pediatric residents, with a $98 \%$ response rate. The SRQ asked residents to assess the effect of sleep deprivation on their general performance and on specific aspects of it. The question was:
"Please rank your performance during your night shift, as you assess it with respect to the following functions."

A list of eleven professional performance components followed, based on "a physician charter" (ABIM, 2002, 2003²), all derived from physicians' core professional performance demands, ${ }^{3}$ which served as key measures. The professional performance components listed were: (a) decision making; (b) ability to concentrate; (c) memory; (d) case analysis; (e) execution of differential diagnosis; (f) reading medical literature; (g) technical ability; (h) quality of patient history acquisition; (i) ability to receive negative feedback; (j) patience towards medical staff; and (k) general functioning. The ranking, on a scale of 1-4, was as follows: 1 - Performance component strongly and negatively affected by sleep loss; 2 - Performance component moderately and negatively affected by sleep loss; 3 - Performance component not affected by sleep loss; and 4 - Performance component positively affected by sleep loss. Reliability tests (Cronbach's alpha) of this scale showed the components to be reliable (á=0.85) and suitable for employment in this study.

\section{PROCEDURE}

Each participant played the Tetris computer game until he/she lost a game (about 10 minutes). We then recorded each respondent's best result out of the total number of games played. The respondents were invited to play the TCG on two separate occasions, both at 8 a.m.: (a) once upon commencement of an 8-hour day shift and (b) once upon the nominal conclusion of a night shift (i.e., after 16 hours on duty). During night shifts sleep is limited, and usually interrupted; however only those respondents reporting being awake during at least part of the night shift were included in this study. The two objective measurements were both made at 8 a.m., thus reducing performance biases related to their timing. The third measure, (c), representing the percentage of performance change, was computed for each player by calculating the percentage of change between the best (a) and (b) scores along with the direction of change. Thus, the (c) values for players who gained higher scores at the start of day shift than those gained after a night shift were positive, while (c) values for players for whom the reverse was true were negative.

Fifty-eight participants $(37.9 \%)$ were not 
acquainted with the Tetris game and needed instruction and a demonstration. T-Tests show no significant gender differences amongst those previously acquainted with the Tetris game (mean=-0.73, s.d. $=1.086, \mathrm{t}=-4.442$, $\mathrm{p}>0.05$ ).

Following completion of the TCG, we presented the respondents with the self-report questionnaire (SRQ). They filled out the SRQ only once, at the nominal conclusion of their night shift at 8 a.m. Completed questionnaires were collected immediately. This presentation order was followed to prevent the questionnaire variables (concentration, decision-making, etc.) from affecting the subjects' objective performances, for example by creating a situation whereby their actual performance could be affected by their self-assessed concentration levels or decision-making abilities (see Dorrian et al., 2003; Rogers and Dinges, 2003). However, in the following sections we describe and discuss the tests in the reverse order (i.e. first the subjective, self-assessment, data, then the objective data), as this order better suits that of the hypotheses presented above.

All the parameters evaluated by the subjective and objective tools are relevant to clinical performance (ABIM Foundation, 2002; ABIM Foundation; ACP-ASIM, 2003). However, each tool (the SRQ and the TCG) assessed different performance determinants. These two measurement tools were employed in our study in order to broaden the empirical spread of this study and not in order to validate each tool's relevance.

\section{RESULTS AND DATA ANALYSIS}

Prior to the investigation of this study's hypotheses we tested for the possible presence of significant differences, in terms of this study's measures, between the respondents from the different hospitals. The results from the ANOVA show no such significant differences (gender: $F(2$, $144)=0.92, p>0.05$; seniority: $F(2,144)=0.22$, $p>0.05$; the mean number of night shifts per month: $F(2,144)=3.26, p>0.05$; and the mean amount of sleep during a night shift: $F(2$, 144) $=1.10, p>0.05)$.

\section{The Subjective Measure (SRQ)}

To investigate the first hypothesis, that women report a greater decline in performance after a night shift than do men, we performed a multivariate analysis of variance (MANOVA). The MANOVA used all eleven of the professional performance components listed in the SRQ (see Methods: The Subjective Tool) as dependent variables and gender as a covariate. The analysis reveals that according to residents' selfassessments, gender has a significant main effect on the performance of professional functions after a night shift (Wilks ë $=0.695, F(1,149)=1.48$, $p<0.05)$. No interaction between the main effects was found. However, the follow-up test of Between Subjects Effects reveals a relationship between gender and self-assessments in five performance components: decision making; execution of differential diagnosis; reading medical literature; technical ability; and general function.

The descriptive results show the following: approx. $16 \%$ of men and $83 \%$ of women assess that a sleep-deprivation has strong and negative effects on their decision making; approx. $41 \%$ of men and $59 \%$ of women report that it has strong and negative effects on execution of differential diagnosis; about $53 \%$ of men and $46 \%$ of women report that it has strong and negative effects on reading medical literature; and about $33 \%$ of men and $66 \%$ of women assess that a night shift has strong and negative effects on both technical ability and general functioning. Thus, except with respect to reading medical literature, a greater percentage of women than men consider a night shift very detrimental to their performance, and that whereas only a minority of the men surveyed feel themselves to be thus affected, a majority of the women surveyed hold this view.

\section{The Objective Measure (TCG)}

To investigate the second hypothesis, that there are no significant objective differences between the changes in men and women physicians' actual performances after a night shift, we employed the Tetris computer game scores. A One-Way ANOVA was performed with Post Hoc Multiple comparisons, and a Bonferroni correction $^{44}$ was employed. Three measures of Tetris performance $(\mathrm{a}, \mathrm{b}$ and $\mathrm{c}$, as defined in the Procedure section) were used as dependent variables. Gender was included as the independent variable. The ANOVA results should reveal the extent to which there is a gender-based variance in Tetris game performance. Our results show no significant gender effect in any of the measures 
of the Tetris scores. Subsequent descriptive tests were employed. The descriptive results show that the men's mean Tetris scores (mean=13,112; s.d. $=16,222)$ are higher than the women's $($ mean $=12,878$; s.d. $=13,712)$ at the start of a day shift, while the women's mean scores (mean=10,204; s.d.=11,829) are higher after a night shift than the men's (mean=8,437; s.d.=10,037); thus scores decline after the night shift for both genders. However, judging from the ANOVA these results are not significant (Table 1).

\section{Personal and Job-related Determinants}

In order to decipher the net and direct effects of sleep-deprivation on men's and women's' selfassessment and objective performance we included the seven personal and job-related

Table 1: Regression analyses using the self-report data, with the professional performance components as dependent variables and the personal and job-related determinants as independent variables.

\begin{tabular}{|c|c|c|c|c|}
\hline Decision Making & $B$ & $\beta$ & $t$ & $P$ \\
\hline Number of night shifts per month & 1.633 & .030 & .219 & .828 \\
\hline Average hours of sleep per night shift & -.149 & -.154 & -1.101 & .279 \\
\hline Actual hours of sleep during the night shift just ended & .158 & .363 & 2.358 & $.024 *$ \\
\hline $\begin{array}{l}\text { Self assessment of the complexity of the night } \\
\text { shift just ended }\end{array}$ & .281 & .295 & 1.772 & .086 \\
\hline $\begin{array}{l}\text { Number of hours into a night shift after which } \\
\text { performance begins to decline }\end{array}$ & 6.664 & .539 & 3.941 & $.000 * *$ \\
\hline Number of years of seniority in the specialization program & 4.549 & .094 & .628 & .534 \\
\hline Gender & -.375 & -.287 & -2.115 & $.042 *$ \\
\hline \multicolumn{5}{|l|}{$\mathrm{R}=.688 ; \mathrm{R}^{2}=.474 ;$ Adj $\mathrm{R}^{2}=.362$; F Change $(7,53)=4.248 ; \mathrm{p}<.002 * *}$. \\
\hline Reading Medical Literature & $B$ & $\beta$ & $t$ & $P$ \\
\hline Number of night shifts per month & -2.041 & -.068 & -.436 & .666 \\
\hline Average hours of sleep per night shift & -6.759 & -.128 & -.798 & .431 \\
\hline Actual hours of sleep during the night shift just ended & 7.173 & .300 & 1.705 & .098 \\
\hline $\begin{array}{l}\text { Self assessment of the complexity of the night shift } \\
\text { just ended }\end{array}$ & -7.845 & -.150 & -.789 & .436 \\
\hline Number of hours into a night shift after which & & & & \\
\hline performance begins to decline & 1.007 & .148 & .950 & .349 \\
\hline Number of years of seniority in the specialization program & 8.876 & .333 & 1.955 & $.050 *$ \\
\hline Gender & -.235 & -.327 & -2.107 & $.043^{*}$ \\
\hline \multicolumn{5}{|l|}{$\mathrm{R}=.559 ; \mathrm{R}^{2}=.312 ;$ Adj $\mathrm{R}^{2}=.166 ; \mathrm{F}$ Change $(7,53)=2.141 ; \mathrm{p}<.050 *$. } \\
\hline General Functioning & $B$ & $\hat{a}$ & $t$ & $P$ \\
\hline Number of night shifts per month & 3.320 & .072 & .503 & .619 \\
\hline Average hours of sleep per night shift & -.353 & -.439 & -2.956 & $.006 * *$ \\
\hline Actual hours of sleep during the night shift just ended & .137 & .378 & 2.315 & $.027 *$ \\
\hline $\begin{array}{l}\text { Self assessment of the complexity of the night shift } \\
\text { just ended }\end{array}$ & .165 & .208 & 1.178 & .247 \\
\hline $\begin{array}{l}\text { Number of hours into a night shift after which } \\
\text { performance begins to decline }\end{array}$ & 3.408 & .331 & 2.278 & $.029 *$ \\
\hline Number of years of seniority in the specialization program & 6.858 & .017 & .107 & .915 \\
\hline Gender & -.264 & -.242 & -1.679 & $.050 *$ \\
\hline
\end{tabular}

$\mathrm{R}=.637 ; \mathrm{R}^{2}=.406$; Adj $\mathrm{R}^{2}=.280$; F Change $(7,53)=3.227$; $\mathrm{p}<.010^{* *}$.

Summary of statistics for the remaining eight professional performance components:

Concentration ability: $\mathrm{R}=.468 ; \mathrm{R}^{2}=.219 ;$ Adj $\mathrm{R}^{2}=.053 ; \mathrm{F}$ Change $(2,265)=1.319 ; \mathrm{p}=.272$

Memory R=.427; $\mathrm{R}^{2}=.182 ;$ Adj $\mathrm{R}^{2}=.009 ; \mathrm{F}$ Change $(7,53)=1.052 ; \mathrm{p}=.415$

Case analysis $\mathrm{R}=.526 ; \mathrm{R}^{2}=.277 ;$ Adj $\mathrm{R}^{2}=.123 ; \mathrm{F}$ Change $(7,53)=1.802 ; \mathrm{p}=.120$

Execution of differential diagnosis $\mathrm{R}=.535 ; \mathrm{R}^{2}=.287$; Adj $\mathrm{R}^{2}=.135 ; \mathrm{F}$ Change $(7,53)=1.895 ; \mathrm{p}=.102$

Technical ability $\mathrm{R}=.452 ; \mathrm{R}^{2}=.205$; Adj $\mathrm{R}^{2}=.036$; F Change $(7,53)=1.213 ; \mathrm{p}=.323$

Quality of patient history acquisition $\mathrm{R}=.473 ; \mathrm{R}^{2}=.223$; Adj $\mathrm{R}^{2}=.059 ; \mathrm{F}$ Change $(7,53)=1.355 ; \mathrm{p}=.257$

Ability to receive negative feedback $\mathrm{R}=.489 ; \mathrm{R}^{2}=.239$; $\operatorname{Adj} \mathrm{R}^{2}=.078$; F Change $(7,53)=1.481 ; \mathrm{p}=.208$

Patience towards medical staff $\mathrm{R}=.405 ; \mathrm{R}^{2}=.164 ; \operatorname{Adj} \mathrm{R}^{2}=-.014 ; \mathrm{F}$ Change $(7,53)=.922 ; \mathrm{p}=.502$

Note: $\mathrm{p}^{*<.050} \mathrm{p}^{* *<.010}$ 
determinants (see Methods: Study population). (a) We performed regression analyses for each professional performance component in an Enter method, utilizing each one of the eleven professional performance components listed in the SRQ (see Methods: The subjective tool) as the dependent variable, and employing the personal and job-related determinants as independent variables.

Significant results (see Table 1) emerge from three equations: decision making; reading medical literature; and general functioning. Gender appears as a significant predictor of selfreported performance after a night shift in the same three equations, namely, decision-making, reading medical literature and general functioning. Consistent with the previous results (Table 1), again except for reading medical literature, and based on their self-assessments, a greater proportion of women than men report that sleep deprivation strongly and negatively affects these components of their professional performance.

Other interesting results relate to actual hours of sleep per night shift, which as the SRQ data indicate positively affects decision-making, reading medical literature and general functioning, as well as average hours of sleep per night shift, which predicts general functioning. Seniority in their field of specialization emerges as a significant parameter influencing reading medical literature.

(b) We performed a second series of Regression analyses on the data from the Tetris games, using the percentage change in performance values as the dependent variable and the seven personal and job-related determinants as independent variables. The Regression equation results (Table 2) are not significant; indicating that none of the seven determinants investigated is able to significantly explain the observed changes in Tetris performance after a night shift compared to those observed at the start of a day shift.

\section{DISCUSSION}

Sleep deprivation is known to contribute to the human error component in medical treatment. Hospital physicians' function around the clock; they typically work long hours and are often sleep deprived, factors that have a detrimental impact in their performance of clinical tasks.

In view of these known and accepted facts, the present study attempted to explore whether there are gender-related differences in physicians' ability to perform job-related tasks, and in men and women hospital physicians' self-assessments of their performance when sleep deprived.

Performance of clinical tasks is a multi-faceted undertaking, while its empirical exploration is based to a large extent on uni-dimensional tools. In the present study, in order to overcome possible biases related to performance measurements (discussed in the Introduction), we employed two different tools, both reflecting versatility of performance. By incorporating subjective assessments (selfreports of performance) and objectively measured performance of tasks (a computer game), we measured both outcome and process.

Although it is generally accepted that the power of the combination of objective and

Table 2: Regression analysis using the objective Tetris game-play data, with professional performance components ${ }^{1}$ as dependent variables and personal and job-related determinants as independent variables

\begin{tabular}{|c|c|c|c|c|}
\hline Percentages and direction of performance change & $B$ & $\beta$ & $t$ & $P$ \\
\hline Number of night shifts per month & -15.716 & -.310 & -1.996 & $.050 *$ \\
\hline Average hours of sleep per night shift & 26.048 & .293 & 1.827 & .077 \\
\hline Actual hours of sleep during the night shift just ended & -19.469 & -.486 & -2.752 & $.010^{* *}$ \\
\hline $\begin{array}{l}\text { Self assessment of the complexity of the night } \\
\text { shiftjust ended }\end{array}$ & -14.274 & -.163 & -.853 & .400 \\
\hline $\begin{array}{l}\text { Number of hours into a night shift after which } \\
\text { performance begins to decline }\end{array}$ & -2.094 & -.184 & -1.174 & .249 \\
\hline Number of years of seniority in the specialization progran & .411 & .009 & .054 & .957 \\
\hline Gender & -10.524 & -.088 & -.562 & .578 \\
\hline
\end{tabular}

$\mathrm{R}=.554 ; \mathrm{R}^{2}=.307$; Adj $\mathrm{R}^{2}=.160 ; \mathrm{F}$ Change $(2,265)=2.090 ; \mathrm{p}>.050$.

Note: $\mathrm{p} *<.050 \mathrm{p} * *<.010$

1 The eleven professional performance components are: (1) decision making; (2) ability to concentrate; (3) memory; (4) case analysis; (5) execution of differential diagnosis; (6) reading medical literature; (7) technical ability; (8) quality of patient history acquisition; (9) ability to receive negative feedback; (10) patience towards medical staff; and (11) general functioning. 
subjective measures is greater in situations in which the measures agree, we consider the most interesting finding in our results the fact that the respondents' objectively measured performance diverges from their self-reports of performance. Such a divergence implies that men and women hospital physicians continue to have specific and biased gender-based perceptions of their professional capabilities. A population of residents specializing in pediatrics was chosen for this study in order to ensure greater homogeneity and minimize possible indirect effects of specialization type on our research findings (Gjerberg, 2002).

Our first hypothesishas been partially supported by our findings, which revealed differences in the men and women residents' selfassessments in several performance components. These results appear to accord with the literature showing that women perceive a deterioration in their performance when sleep-deprived more than do men, despite the fact that no gender differences emerged in objective performance measures (Dijk et al., 1993; Fulco et al., 2001).

Our second hypothesis, that no differences would emerge in men's and women's objective performance, was explored through the use of a Tetris computer game that the respondents played once in a normal situation and once in a sleepdeprived situation; the scores achieved were compared in order to assess the differences in performance in the two situations. The results of this comparison indicated an absence of significant gender differences in performance, thus confirming our second hypothesis. Nevertheless, means of the men and women physician's best TCG scores after a night-shift or before a day shift do differ: on average men physicians scored higher than women physicians at the start of a day shift, while women scored higher than men after a night shift. Since the results obtained were not statistically significant, gender performance should be re-examined in future research using a broader population of physicians. Despite its limitations, the results are in agreement with the empirical findings, discussed in the body of this paper, of certain bio-psychological gender differences that indicate that fatigue develops more slowly in women than in men, an attribute that could explain women's higher performance scores after a night shift (Fulco et al., 2001; Mourtazaev et al., 1995).

The last step was the evaluation of the net effect of gender on self-assessment, along with the effect of any other gender-related variables that might indirectly influence the respondents' self-assessments and their objective performance. The analyses revealed that there were three performance components regarding which women physicians reported a decline in performance after a night shift in which their male counterparts did not: decision-making, reading medical literature and general functioning. No significant results emerged from the regression employing the computer game as a dependent variable.

Overall, these results reveal discrepancies between women's objective performance and their subjective assessment of their performance when experiencing sleep loss, although the discrepancies were not in the same performance domains. This contradiction is consistent with several studies in the fields of military psychology and aviation that show some degree of inconsistency between performance tests in sleep-deprived situations and self-evaluations (Baransk et al., 2002; LeDuc et al., 2000). Although the latter studies did not refer specifically to gender differences, they did indicate inconsistencies between participants' cognitive performance as evaluated by objective measures of performance of batteries of tasks and subjective assessments of performance.

\section{IMPLICATIONS AND LIMITATIONS}

The main contribution of our study is its findings regarding the comparative assessments of men and women hospital physicians of the effects that sleep debts have on the clinical tasks they must perform, and in delineating real versus presupposed differences in actual performance of tasks when fatigued by sleep loss. We deciphered these findings while controlling for objective parameters of the women physicians' subjective acceptance of the traditional assessments of women's - and women physicians' among them lesser strengths. Acceptance, by both sexes, of such differences between men's and women's abilities to perform tasks competently in sleepdeprived situations highlights the continued agreement with the traditional views of gendered capabilities. These are important contributions to academic research as well as to organizational endeavors to fully integrate women in the medical workforce and to allow for their professional advancement. 
The results of our study clearly confirm that reliance on one measurement tool will yield biased and incomplete results (Solomon and Ferenchick, 2005), and strongly suggest that multi-faceted measures should be implemented in the hospital routine in order to monitor physicians' sleep debts and the impact of these on the different measures of their performance. This study's results also clearly demonstrate the need to raise the awareness of hospital managements to the relationship between performance of clinical tasks and sleep loss, and to focus on the selfconfidence of women physicians regarding their performance when affected by sleep-deprivation.

Since this research is based on a fairly small study/sample population from only three Israeli hospitals, in future research the number of respondents should be expanded in order to trace the different affects of sleep debts among the genders on their different professional tasks. Future research should sample a larger number of medical centers and include physicians from a range of specialties. Moreover, though the Tetris in our study provided useful insights into the some relevant objective measures of performance while sleep deprived, of both men and women physicians, more finely-adjusted tools should be developed and implemented in hospitals in order to assess physicians' abilities and performance when affected by sleep debts. The virtual simulations, used at present in hospitals for training and assessment are usually complex and require specific expertise from the evaluator; they are also expensive and, finally, can be biased by the evaluators' perspectives. Moreover, we were unable to locate any empirical study employing virtual simulations for sleep deprivation assessment and prevention. Such assessment tools lack in the research field, as well.

\section{NOTES}

1 All three medical centers are public hospitals. Two of the centers are general hospitals and one is a pediatric hospital. All three hospitals are located in the metropolitan area of Tel Aviv and serve a broad range of patients.

2 ABIM Foundation. American Board of Internal Medicine; ACP-ASIM Foundation. American College of Physicians-American Society of Internal Medicine; European Federation of Internal Medicine. (2002). Medical professionalism in the new millennium: A physician charter. Annals of Internal Medicine, 136(3), 243-246.

ABIM Foundation; ACP-ASIM Foundation; European Federation of Internal Medicine (2003). Medical professionalism in the new millennium: a physician charter. Journal of the American College of Surgeons, 196(1), 115-118.

3 cognitive abilities - decisiveness, problem-solving coupled with effective decision-making in a timely manner, adaptability to change, and ability to concentrate; (2) communication skills - the ability to ensure secure and readily accessible communication among clinicians and patients and to improve administrative efficiencies for the benefit of the patient; and (3) job-related knowledge - the ability to diagnose patients accurately and to rapidly access key information (ABIM Foundation, 2002; ACP-ASIM Foundation, 2003; McManus, Winder and Gordon, 2001; Proctor and Cambell, 1999).

4 By correcting the alpha level using the Bonferroni correction, which controls for alpha errors, we avoid the problem of significant results being due to chance.

\section{REFERENCES}

Ancoli-Israel, S. and M. B. Weinger. 2002. "Sleep deprivation and clinical performance." JAMA, 287: 955-957.

Angus, J. and I. L. Bourgeault. 1998. "Medical dominance, gender and the state: The nurse practitioner initiative in Ontario." Health and Canadian Society, 5(1): 55-81.

Baranski, J. V., V. Gil, T. McLellan and D. Moroz. 2002. "Effects of Modafinil on cognitive perfor-mance during $40 \mathrm{hr}$ of sleep deprivation in a warm environment." Military Psychology, 14: 23-47.

Bensing, J. M., A. van den Brink-Muinen and D. de Bakker. 1993. "Gender Differences in Practice Style: A Dutch Study of General Practitioners." Medical Care, 31: 219-229.

Beyer, S. 1995. "Gender Differences in the Accuracy of Self-Evaluations of Performance." Journal of Personality and Social Psychology, 59: 960-970.

Beyer, S. and E. M. Bowden. 1997. "Gender differences in self-perceptions: Convergent evidence from three measures of accuracy and bias." Personality and Social Psychology Bulletin, 23(2): 157-172.

Brienza, R. S., S. Huot and E. S. Holmboe. 2004. "Influence of gender on the evaluation of internal medicine residents." Journal of Women's Health, 13(1): 77-83.

Britt H., A. Bhasale, D. A. Miles, A. Meza, G. P. Sayer and M. Angelis. 1996. "The sex of the general practitioner: A comparison of characteristics, patients, and medical conditions managed." Medical Care, 34(5): 403-415.

Bonanno, P. and P. A. Kommers. 2005. "Gender differences and styles in the use of digital games." Educational Psychology, 25(1): 13-42.

Caldwell, J.A. and P.A. Leduc. 1998. "Gender influences on performance, mood and recovery sleep in fatigued aviators." Ergonomics, 41(12): 1757-1770.

Chelette, T. L., W.B. Albery, R.L. Esken and L.D. Tripp. 1998. "Female exposure to high G: performance of simulated flight after 24 hours of sleep deprivation." Aviation, Space and Environ-mental Medicine, 69(9): 862-868.

Crossley, J. and H. Davis. 2005. "Doctors' consultations with children and their parents: A model of 
competencies, outcomes and confounding influences." Medical Education, 39(8): 807-819.

Defoe, D. M., M. L. Power, G. B. Holzman, A. Carpentieri and J. Schulkin. 2001. "Long hours and little sleep: Work schedules of residents in obstetrics and gynecology." Obstetrics and Gynecology, 97: 10151018.

Demaine, E. D., S. Hohenberger and D. Lieben-Nowell 2004. "Tetris is Hard, Even to Approximate." International Journal of Computational Geometry and Applications, 14(1-2): 41-68.

Dorrian, J., N. Lamond and D. Dawson. 2000. "The ability to self-monitor performance when fatigued." Journal of Sleep Research, 9: 137-144.

Dorrian, J., N. Lamond, A. L. Holmes, H. J. Burgess, G. D. Roach, A. Fletcher and D. Dawson. 2003. "The Ability to Self-Monitor Performance During a Week of Simulated Night Shifts.” Sleep, 26: 871-877.

Dula, D. J., N. L. Dula, C. Hamrick and G. C. Wood 2001. "The effect of working serial night shifts on the cognitive functioning of emergency physicians." Annals of Emergency Medicine, 38: 152-155.

Eagly, A. H. and W. Wood. 1999. "The origins of sex differences in human behavior: Evolved dispositions versus social roles." American Psychologist, 54: 408423.

Eddy, D. M. 1998. "Performance measurement: Problems and solutions." Health Affairs, 17(4): 7-26.

Fiske, S. T., A. J. C. Cuddy, P. Glick and S. Xu. 2002. "A model of (often mixed) stereotype content: Competence and warmth respectively follow from perceived status and competition." Journal of Personality and Social Psychology, 82: 878-902.

Fletcher, A., N. Lamond, C. van den Heuvel and D. Dawson. 2003. "Prediction of Performance during Sleep Deprivation and Alcohol Intoxication using a Quantitative Model of Work-Related Fatigue." Sleep Research Online, 5(2): 67-75.

Foschi, M. 1996. "Double Standards in the Evaluation of Men and Women." Social Psychology Quarterly, 59(3): 237-254.

Fulco, C. S., P. B. Rock, S. R. Muza, E. Lammi, B. Braun, A. Cymerman, L.G. Moore and S. F. Lewis. 2001. "Gender alters impact of hypobaric hypoxia on adductor pollicis muscle performance." Journal of Applied Physiology, 91: 100-108.

Furnham, A. 2005. Gender and Personality Differences in Self-and Other Ratings of Business Intelligence. British Journal of Management, 16(2): 91-103

Gillberg, M., G. Kecklund, J. Axelsson and T. Akerstedt. 1996. "The effects of a short daytime nap after restricted night sleep." Sleep, 19: 570-575.

Gjerberg, E. 2002. "Gender similarities in doctors' preferences-and gender differences in final specialization." Social Science and Medicine, 54(4): 481-642.

Gneezy, U. M. Niederle and A. Rustichini. 2003. "Performance in competitive environments: Gender differences." Quarterly Journal of Economics, 10491074.

Grantcharov, T.P. L. Bardram, P. Funch-Jensen and J. Rosenberg. 2001. "Laparoscopic performance after one night on call in a surgical department: Prospective study." British Medical Journal, 323: 1222-1224.
Grantcharov, T. P., L. Bardram, P. Funch-Jensen and J. Rosenberg. 2003. "Impact of hand dominance, gender, and experience with computer games on performance in virtual reality laparoscopy." Surgical Endoscopy, 17(7): 1082-1085.

Griffith, J. R., J. A. Alexander and G. L. Warden. 2002. "Measuring comparative hospital performance / Practitioner response." Journal of Healthcare Management, 47(1): 41-58.

Gorman, E. H. 2005. "Gender Stereotypes, Same-Gender Preferences, and Organizational Variation in the Hiring of Women: Evidence from Law Firms." American Sociological Review, 70(4): 702-729.

Guzman, M.C. and J. Frank. 2004. "Policewomen and their problems: The Philippine context." Policing, 27(3): 396-412.

Haier, R. J., B. V. Siegel, A. MacLachlan, E. Soderling, S. Lottenberg and M. S. Buchsbaum. 1992. "Regional glucose metabolic changes after learning a complex visio spatial/motor task: A positron emission tomographic study." Brain Research, 570: 134-143.

Hall, E. G. 1990. "The Effect of Performer Gender, Performer Skill Level, and Opponent Gender on Self-Confidence in a Competitive Situation." Sex Roles, 23(1-2): 33-42.

Hall, J. A., R. H. Palmer, E. J. Orav, J. L. Hargraves, E. A. Wright and T. A. Louis. 1990. "Performance quality, gender, and professional role. A study of physicians and nonphysicians in 16 ambulatory care practices." Medical Care, 28(6): 489-501.

Halpern, D. F. 2000. Sex Differences in Cognitive Abilities ( $3^{\text {rd }}$ ed.). Mahwah, NJ: Lawrence Erlbaum Associates.

Halpern, D. F. and L. M. LaMay. 2000. "The smarter sex: A critical review of sex differences in intelligence." Educational Psychology Review, 12: 229-246.

Harma M., P. Knauth and J. Ilmarinen, 1989. "Daytime napping and its effects on alertness and short-term memory performance in shiftworkers." International Archives of Occupational and Environmental Health, 61: 341-345.

Hind, P. and Y. Baruch. 1997. "Gender variations in perceptions of performance appraisal." Women in Management Review, 12(7): 276-289.

Jackson, S. E. and A. Joshi. 2001. "Research on domestic and international diversity in organizations: A merger that works?" (pp. 206-231), N. Anderson, D. Ones, H. Sinangil and C. Visweswaran, (Eds.) Handbook of Industrial, Work and Organizational Psychology, Sage Publications.

Janowsky, J. S., B. Chavez and E. Orwoll. 2000. "Sex steroids modify working memory." Journal of Cognitive Neuroscience, 12: 407-414.

Kavakli, M. and J.R. Thorne. 1999. Protocol Analysis in Modeling Autonomously Reactive Agents in Computer Games, Technical Report: RGAI-01-02, Research Group for Complex Systems, Charles Sturt University, Bathurst, Australia.

Kavakli, M. and J. S. Gero. 2002. "The structure of concurrent cognitive actions: a case study on novice and expert designers." Design Studies, 23: 25-40.

Kelinske, B., B. W. Mayer and K. L. Chen. 2001. "Perceived benefits from participation in sports: a gender study." Women in Management Review, 16(2): 75-84.

Knauth, P. 1995. "Speed and direction of shift rotation." Journal of Sleep Research, 4: 41-46. 
LeDuc, P. A., J. A. Caldwell and P. S. Ruyak, 2000. "The effects of exercise as a countermeasure for fatigue in sleep-deprived aviators." Military Psychology, 12: 249-266.

Legnini, M. W., L. E. Rosenberg, M. J. Perry and N. J. Robertson. 2000. "Where does performance measurement go from here?" Health Affairs, 19(3): 173177.

Lewis, G. B. 1997. "Race, sex, and performance ratings in the federal service." Public Administrative Review, 57(6): 479-490.

Lovaglia, M. J., J. W. Lucas, J. A. Houser, S. R. Thye and B. Markovsky. 1998. "Status processes and mental ability test scores." American Journal of Sociology, 104(1): 195-228.

Matuszek, P. A. C., D. L. Nelson and J.C. Quick. 1995. "Gender differences in distress: Are we asking all the right questions?" Journal of Social Behavior and Personality, 10: 99-120.

Maurer, T. J. and M. A. Taylor. 1994. "Is sex by itself enough? An exploration of gender bias issues in performance appraisal." Organizational Behavior and Human Decision Processes, 60: 231-251.

Mourtazaev, M. S., B. Kemp, A. H. Zwinderman and H. A. Kamphuisen, 1995. "Age and gender affect different characteristics of slow waves in the sleep EEG.” Sleep, 18(1): 557-564.

Naglieri, J. A. and J. Rojahn. 2001. "Gender differences in planning, attention, simultaneous, and successive (PASS) cognitive processes and achievement." Journal of Educational Psychology, 93: 430-437.

Papp K. K. E. P. Stoller, P. Sage, J.E. Aikens, J. Owens, A. Avidan, B. Phillips, R. Rosen and K.P. Strohl. 2004. "The effects of sleep loss and fatigue on resident-physicians: a multi-institutional, mixedmethod study." Academic Medicine, 79: 394-406.

Pazy, A. and I. Oron. 2001. "Sex proportion and performance evaluation among high-ranking military officers." Journal of Organizational Behavior, 22(6): 689-702.

Pillay, H. 2002. "An investigation of cognitive processes engaged in by recreational computer game players: Implications for skills of the future." Journal of Research on Technology in Education, 34: 336350 .

Rappaport, A.T. 1997. Context, Cognition, and the Future of Intelligent Infrastructures, (pp. 523-539) in P. J., Feltovich, K. M. Ford and R. R. Hoffman (eds.), Expertise in Context. Menlo Park California, AAAI Press.

Raz, P., G. M. Jensen, J. Walter and L. M. Drake. 1991. "Perspectives on gender and professional issues among female physical therapists." Physical Therapy, 71(7): 530-540.

Ridgeway, C. L. and S. J. Correll. 2000. "Limiting gender inequality through interaction: the end(s) of gender." Contemporary Sociology, 29(1): 110-120.

Rinehart, J. S. and I.P. Young. 1996. "Effects of teacher gender and principal gender on the ratings of teacher performance." Journal of Personnel Evaluation in Education, 10: 313-323.

Robbins, T. L. and A. S. DiNisi. 1993. "Moderators of sex bias in the performance appraisal process: A cognitive analysis." Journal of Management, 19: 113-126.

Rogers, N. L. and D. F. Dinges. 2003. "Subjective surrogates of performance during night work." Sleep, 26(7): 871-877.

Rosekind, M. R., D. L. Miller, K. B. Gregory and D. F. Dinges. 1995. "Flight crew sleep in long-haul aircraft bunk facilities: Survey results." Sleep Research, 524: 112.

Sider, M. A., G. George and R. Dharwadkar. 2001. "The relationship of internal and external commitment foci to objective job performance measures." Academy of Management Journal, 44(3): 570-580.

Smith-Coggins, R., M. R. Rosekind, S. Hurd, and K. R. Buccino. 1994. "Relationship of day versus night sleep to physician performance and mood." Annals of Emergency Medicine, 24: 928-934.

Solomon, D. J. and G. Ferenchick. 2005. "Sources of measurement error in an ECG examination: Implications for performance-based assessments." Advances in Health Sciences Education, 9(4): 283290.

Steele, C. M. 1997. "A threat in the air: How stereotypes shape intellectual identity and performance." American Psychologist, 52: 613-629.

Sturman, M. C., R. A. Cheramie and L. H. Cashen. 2005. "The consistency, stability, and test-retest reliability of employee job performance: A meta-analytic review of longitudinal findings." Journal of Applied Psychology, 90: 269-283.

Suwa, M., J. S. Gero and T. Purcell. 1998. "Macroscopic analysis of design processes based on a scheme for coding designers' cognitive actions." Design Studies 19: 455-483

Taffinder, N. J., I.C., McManus, Y. Gul, C.J. Russel and A. Darzi. 1998. "Effect of sleep deprivation on surgeons' dexterity on laparoscopy simulator." The Lancet, 352: 1191-1195.

Treasure, T. O. Valencia, C. Sherlaw-Johnson and S. Gallivan. 2002. "Surgical performance measurement." Health Care Management Science, 5: 243-248

Viswesvaran, C., D. S. Ones and F. L. Schmidt. 2005. "Is There a General Factor in Ratings of Job Performance? A Meta-Analytic Framework for Disentangling Substantive and Error Influences." Journal of Applied Psychology, 90(1): 108-131.

Wagner, D. C. and J. B. Berger. 1997. "Gender and interpersonal task behaviors: Status expectation accounts." Sociological Perspectives, 40: 1-32.

Watson, J. 2002. "Comparing the Performance of Maleand Female-Owned Businesses: Relating Outputs to Inputs." Entrepreneurship Theory and Practice 26(3): 91-100.

Wilson, F. 2005. "Caught between difference and similarity: the case of women academics." Women in Management Review, 20(3-4): 234-249.

Winstead, B. A., V. J. Derlega and P. T. Wong. 1984. "Effects of sexrole orientation on behavioral selfdisclosure." Journal of Research in Personality, 18: $541-553$ 